\title{
Correction to: Existence of immune cells in uterine luminal flush of repeat breeding Egyptian buffalo-cow (Bubalus bubalis): salpingitis and endometritis as a major cause
}

\author{
Ahmed Essam Elweza ${ }^{1} \cdot$ Enas Abd El-aziz Tahoun ${ }^{2} \cdot$ Ibrahim Said Abu-Alya $^{3} \cdot$ Hamed Talaat Elbaz $^{1}$ \\ Published online: 26 August 2020 \\ (C) Springer-Verlag London Ltd., part of Springer Nature 2020
}

Correction to: Comparative Clinical Pathology https://doi.org/10.1007/s00580-020-03128-6

This paper was published without table and figures. The publisher wish to apologize for this oversight.

The original article has been corrected.

Publisher's note Springer Nature remains neutral with regard to jurisdictional claims in published maps and institutional affiliations.

The online version of the original article can be found at https://oi.org/ $10.1007 / \mathrm{s} 00580-020-03128-6$

\footnotetext{
Ahmed Essam Elweza

ahmed.elweza@vet.usc.edu.eg

1 Department of Theriogenology, Faculty of Veterinary Medicine, University of Sadat City, Menofia, Sadat City 32897, Egypt

2 Department of Pathology, Faculty of Veterinary Medicine, University of Sadat City, Menofia, Sadat City 32897, Egypt

3 Department of physiology, Faculty of Veterinary Medicine, University of Sadat City, Menofia, Sadat City 32897, Egypt
} 